\title{
TCPs, WUSs, and WINDs: families of transcription factors that regulate shoot meristem formation, stem cell maintenance, and somatic cell differentiation
}

\author{
Miho Ikeda ${ }^{1}$ and Masaru Ohme-Takagi ${ }^{1,2}$ * \\ ' Division of Strategic Research and Development, Graduate School of Science and Engineering, Satitama University, Saitama, Japan \\ ${ }^{2}$ Research Institute of Bioproduction, National Institute of Advanced Industrial Science and Technology, Tsukuba, Japan
}

\section{Edited by:}

José Manuel Pérez-Pérez, Universidad Miguel Hernandez de Elche, Spain

\section{Reviewed by:}

Munetaka Sugiyama, The University of Tokyo, Japan

Giovanni Sena, Imperial College London, UK

\section{*Correspondence:}

Masaru Ohme-Takagi, Division of Strategic Research and Development, Graduate School of Science and Engineering, Satitama University, 255 Shimo-Okubo, Sakura-ku, Saitama, Saitama 338-8570, Japan e-mail:m-takagi@aist.go.jp
In contrast to somatic mammalian cells, which cannot alter their fate, plant cells can dedifferentiate to form totipotent callus cells and regenerate a whole plant, following treatment with specific phytohormones. However, the regulatory mechanisms and key factors that control differentiation-dedifferentiation and cell totipotency have not been completely clarified in plants. Recently, several plant transcription factors that regulate meristem formation and dedifferentiation have been identified and include members of the TEOSINTE BRANCHED1/CYCLOIDEA/PROLIFERATING CELL FACTOR (TCP), WUSCHEL (WUS), and WOUND INDUCED DEDIFFERENTIATION (WIND1) families. WUS and WIND positively control plant cell totipotency, while TCP negatively controls it. Interestingly, TCP is a transcriptional activator that acts as a negative regulator of shoot meristem formation, and WUS is a transcriptional repressor that positively maintains totipotency of the stem cells of the shoot meristem. We describe here the functions of TCP, WUS, and WIND transcription factors in the regulation of differentiationdedifferentiation by positive and negative transcriptional regulators.

Keywords: cell differentiation, transcription factor, activator, repressor

\section{INTRODUCTION}

Generally, differentiated mammalian cells cannot alter their fate or dedifferentiate to acquire pluripotency. Therefore, the technology to produce iPS (induced Pluripotent Stem) cells by expressing specific transcription factors represents a significant breakthrough for animal research (Takahashi and Yamanaka, 2006). In contrast to mammalian cells, plant cells can alter their cell fate and differentiated somatic cells easily dedifferentiate to form masses of totipotent cells, called callus, following treatment with the phytohormones auxin and cytokinin. A single callus cell can regenerate a whole plant, as shown by carrot somatic embryogenesis (Nomura and Komamine, 1986).

Recent work has identified several key transcription factors that induce cell dedifferentiation. These include members of the TEOSINTE BRANCHED1/CYCLOIDEA/PROLIFERATING CELL FACTOR (TCP), WUSCHEL (WUS), and WOUND INDUCED DEDIFFERENTIATION (WIND) families. TCP transcription factors determine the region where meristem forms during embryogenesis, and thus play a pivotal role in pattern formation (Koyama et al., 2007, 2010). WUSs function in maintenance of stem cell populations in shoot meristems (Laux etal., 1996). WINDs are involved in repair of wound tissues in plants by controlling cell dedifferentiation (Iwase et al., 2011). Analyses of these transcription factors are gradually elucidating the molecular mechanisms that control differentiation and dedifferentiation of plant cells, showing that these mechanisms involve a fine balance of the activities of positive and negative regulators.
In this mini review, we describe the functional roles of TCP, WUS and WIND transcription factors in the control of plant cell differentiation and the molecular mechanisms of differentiationdedifferentiation, as regulated by positive and negative transcriptional regulators.

\section{TCP TRANSCRIPTION FACTORS FUNCTION AS NEGATIVE REGULATORS OF MERISTEM FORMATION}

The TCP family transcription factors are plant-specific and contain a conserved DNA binding domain, termed the TCP domain. TCP binds the core motif GGnCC (Kosugi and Ohashi, 2002). TCP transcription factors were identified by analysis of mutants that affect various aspects of plant development (Luo et al., 1996; Doebley et al., 1997; Kosugi and Ohashi, 1997; Cubas et al., 1999). For example, the cincinnata (cin) mutant of Antirrhinum majus, which encodes an ortholog of Arabidopsis thaliana TCP3 or TCP4, exhibits abnormal curvature of leaves and petals (Nath et al., 2003; Crawford et al., 2004). In Arabidopsis, the miR319 (JAW) targets TCP2, TCP3, TCP4, TCP10 and TCP24, and the ectopic expression of miR319/JAW results in a cin-like phenotype (Palatnik et al., 2003).

The Arabidopsis genome contains 24 genes encoding TCP transcription factors in two subfamilies, CYC/TB and PCF (Cubas, 2000). Analysis of knockout and knockdown mutants has provided limited information on the biological functions of TCP transcription factors, probably due to functional redundancy. However, application of chimeric repressor gene silencing technology (CRES-T) has provided additional clarification 
of TCP functions. The CRES-T gene silencing system creates a chimeric repressor by fusing a transcriptional activator (or other DNA-binding protein) to the plant-specific SRDX repression domain. This chimeric repressor dominantly suppresses the target genes of the transcription factor, functioning epistatically to any endogenous and functionally redundant transcription factors. As a result, the transgenic plants that express the chimeric repressor exhibit a phenotype similar to lossof-function mutants of the transcription factor (Hiratsu et al., 2003).

Expression of the TCP3 chimeric repressor (P35S:TCP3SRDX) induced abnormal curvature of leaves similar to P35S:JAW plants, indicating that the phenotype of P35S:TCP3SRDX plants reflects that of loss of function of TCPs (Koyama et al., 2007). The P35S:TCP3SRDX lines with strong phenotypes exhibit ectopic formation of meristems on cotyledons, while the ectopic expression of a mutated TCP3, which lacks the target site for miR319, suppresses meristem formation, indicating that TCP3 negatively regulates meristem formation (Koyama etal., 2007). One of the targets of TCPs is CUP-SHAPED COTYLEDON1, which is the key factor that determines the boundary region where the meristem forms (Aida et al., 1997). P35S:TCP3SRDX plants ectopically express CUC1, showed that TCP transcription factors suppress the formation of meristem via the negative regulation of the expression of CUC genes (Koyama et al., 2007). However, TCP3 acts as a transcriptional activator; therefore, TCP3 might activate the expression of the genes for regulators that suppress the expression of CUCs. Several target genes of TCP3 have been identified (Koyama etal., 2010), and include miR164, ASYMMETRIC LEAVES1 (AS1), INDOLE-3-ACETIC ACID3/SHORT HYPOCOTYL2 (IAA3/SHY2) and SMALL AUXIN UP RNA (SAUR). AS1 and IAA encode regulators of leaf development and auxin signaling, respectively (Byrne et al., 2000; Weijers et al., 2005). SAUR is an auxin-inducible gene (Hagen and Guilfoyle, 2002) but its function has not been identified. miR164 targets CUC1, CUC2, and neighboring NAC genes (Nikovics et al., 2006; Larue et al., 2009).

The TCP genes are ubiquitously expressed, except in the meristem, and suppress meristem formation. In the region where the shoot apical meristem is formed, miR319 suppresses TCP expression, and TCPs activate some suppressor genes including miR164; this results in meristem formation by induction of the expression of CUCs (Figure 1). Therefore, TCPs play an important role in pattern formation by suppressing the formation of ectopic meristem.

\section{WUS MAINTAINS STEM CELL POPULATIONS}

WUSCHEL, a HOMEOBOX family transcription factor, plays a central role in the maintenance of stem cell populations in shoot meristems (Laux et al., 1996; Mayer et al., 1998; Veit, 2004). In loss-of-function WUS (wus-1) mutants, new stem cells do not form in the shoot meristem and the meristem of wus-1 plants stops growing after forming several leaves (Laux et al., 1996). By contrast, ectopic expression of WUS increases the size of shoot meristems and induces ectopic cell dedifferentiation, with resultant formation of adventitious shoots and somatic embryos in root tissues (Zuo et al., 2002; Gallois et al., 2004). These results indicate that WUS positively regulates the size of the shoot meristem by maintaining the appropriate number of pluripotent stem cells. WUS acts as a positive regulator of the expression of CLV3, which encodes a small peptide ligand that negatively regulates meristem size by suppressing the expression of WUS (Schoof et al., 2000; Reddy, 2008). Therefore, feedback regulation between WUS and CLVs finely tunes the size of the meristem (Figure 1). WUS functions as a transcriptional repressor (Ikeda et al., 2009), and thus appears to suppress the expression of a negative regulator of CLV3.

The Arabidopsis WUS family consists of 15 members, WUS and the WUSCHEL-RELATED HOMEOBOX (WOX) genes (Haecker et al., 2004). The WUS family transcription factors contain a conserved WUS-box domain in addition to the homeodomain (Haecker et al., 2004). The WUS-boxes of WUS and 7 WOXs also contain a TLXLFP motif, which functions in repression of transcription (Ikeda et al., 2009). WUS proteins with a mutation in the TLXLFP motif lost activity for maintenance of stem cell population and induction of cell dedifferentiation, and SRDX repression domain is able to complement loss of TLXLFP motif activity in the mutated WUS protein, indicating that the maintenance of stem cell population and induction of cell dedifferentiation require the repressive activity of WUS.

ARABIDOPSIS RESPONSE REGULATOR7 (ARR7), a type A response regulator, negatively regulates cytokinin signaling and suppresses the size of the meristem (Leibfried et al., 2005; Zhao et al., 2010). WUS directly binds to the $5^{\prime}$ region upstream of the ARR7 gene to suppress its expression (Figure 1). Because ARR7 negatively regulates the size of the meristem, suppression of $A R R 7$ by WUS might be important to maintain stem cell populations. The expression of $A R R 7$ and $A R R 15$ is regulated by auxin via activation of AUXIN RESPONSE FACTOR5/MONOPTEROS (Leibfried et al., 2005; Zhao et al., 2010). The expression of ARRs and WUS is positively regulated by cytokinin (Figure 1) (Holt et al., 2014). These observations suggest that type A response regulators regulate differentiation-dedifferentiation of plant cells mediated by WUS, auxin and cytokinin. In addition to ARRs, TOPLESS, CLV1, KANADI1, KANADI2, ASYMMETRIC LEAVES2, and $Y A B B Y$, which are involved in cell differentiation and leaf development, are also direct targets of WUS (Busch et al., 2010; Yadav et al., 2013). WUS may maintain meristematic pluripotent stem cells by suppressing the expression of these genes related to cell differentiation.

\section{WINDs REGULATE CELL DEDIFFERENTIATION DURING THE WOUNDING RESPONSE}

Similar to other multicellular organisms, plants regenerate new organs to repair wounded tissues. In wound repair, somatic cells of wound tissues first dedifferentiate to form a mass of pluripotent cells called callus. Then the callus cells re-differentiate and regenerate the organ. Wound-induced cell dedifferentiation is commonly observed in various multicellular organisms and several key factors that induce meristem formation have been identified (Stappenbeck and Miyoshi, 2009), but the molecular mechanisms that induce the wounded cells into dedifferentiated status during wound repair have not been clarified in plants. 


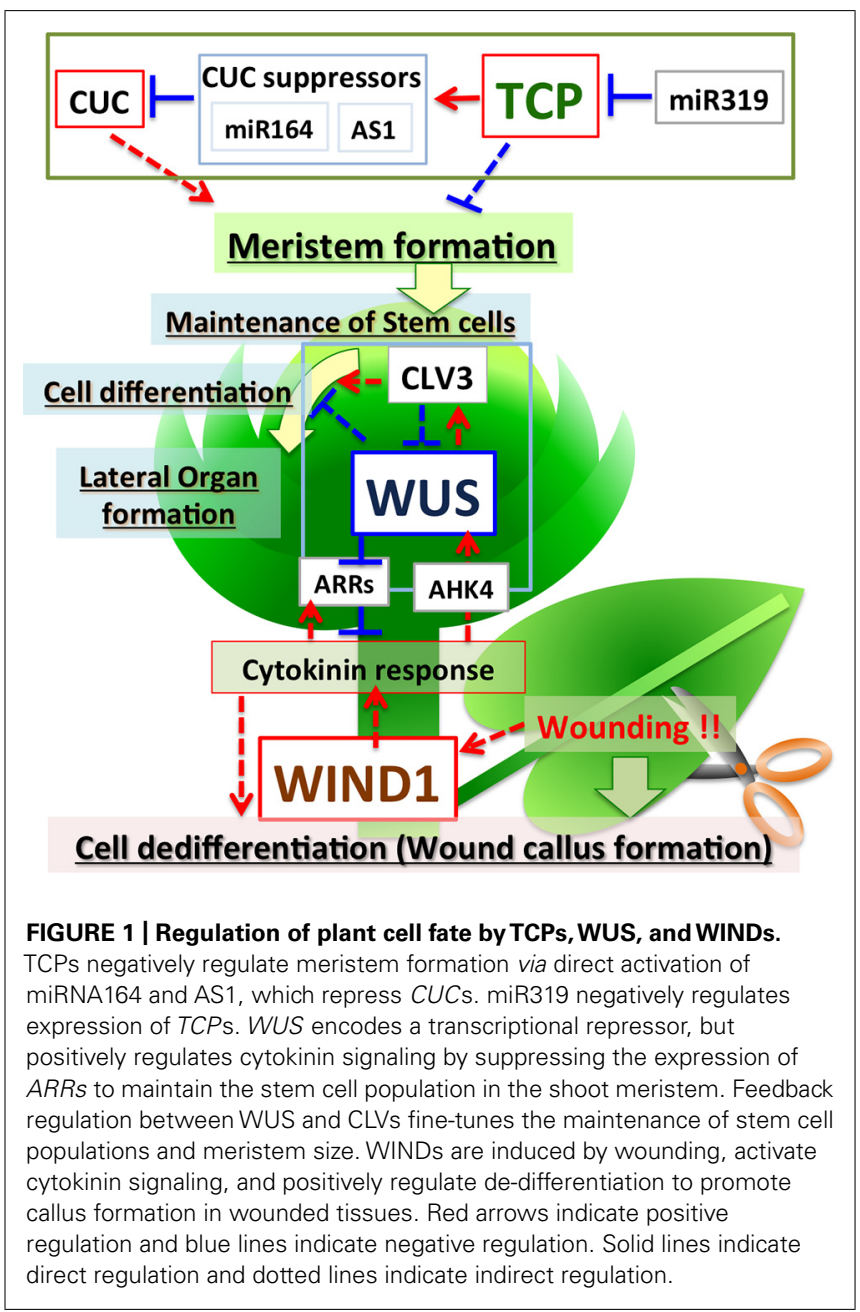

Recent work showed that AP2/ERF transcription factors WIND1, WIND2, WIND3, and WIND4 function as master regulators that control dedifferentiation in plants (Iwase et al., 2011). Comparison of gene expression between Arabidopsis callus and seedlings revealed that WIND1 is specifically expressed in callus. WIND1 is also rapidly induced after wounding and specifically expressed in the wound site. Remarkably, Arabidopsis plants that ectopically express WIND1 (P35S:WIND1) form callus after germination. The P35S:WIND1 callus has similar expression profile to the callus induced by auxin and cytokinin. The expression of WIND1 alone is sufficient to induce cell dedifferentiation to form callus and to maintain callus without auxin or cytokinin; therefore, WIND1 functions as a master regulator of cell dedifferentiation in Arabidopsis. Interestingly, P35S:WIND1 callus does not show increased auxin content or increased activity of the auxin reporter DR5. By contrast, the P35S:WIND1 callus does show increased cytokinin content. P35S:WIND1 enhances callus formation at low cytokinin concentrations, concentrations that do not induce callus production in wild-type Arabidopsis plants. Also, arr1 arr2 mutants, which are defective for type-B ARR-mediated cytokinin signaling, suppress callus formation by P35S:WIND1. These observations suggest that WIND1 induces callus formation by activating cytokinin signaling, but not auxin signaling (Figure 1).

\section{CONCLUSIONS AND FUTURE PROSPECTS}

Recent work has identified factors that regulate differentiationdedifferentiation of plant cells. TCP, WUS, and WIND transcription factors are involved in the regulation of differentiation of plant cells, but each of these transcription factor families has different molecular functions and different roles in controlling cell fate. The TCP genes are highly conserved among plant genomes and form a multigene family with pivotal roles in plant development. TCPs are transcriptional activators, but act as negative regulators of cell dedifferentiation and suppress meristem formation via activation of miRNA164 and AS1 to repress the expression of the CUC genes. TCPs are also negatively regulated by miR319. By contrast, WUS is a transcriptional repressor, but acts as a positive regulator promoting cell dedifferentiation. One of the direct targets of WUS is a type A response regulator, ARR7, which acts as a suppressor of cytokinin signaling. WUS positively regulates cytokinin signaling by suppressing the expression of $A R R 7$. Maintenance of stem cell populations and meristem size are finetuned by feedback regulation between WUS and CLVs. WINDs are transcriptional activators and promote dedifferentiation similar to WUS. WINDs appear to activate cytokinin signaling. Thus, positive regulators and various types of negative regulators control cell differentiation and dedifferentiation. In addition, it is typical in plants that transcriptional repressors (WUS) positively regulate dedifferentiation, and transcriptional activators (TCP) negatively regulate dedifferentiation. Fine tuning systems via suppression of a negative regulator by another negative regulator, thus resulting in positive regulation, appears to be employed in the regulation of cell differentiation-dedifferentiation in plants.

As a future step, it will be necessary to identify all the factors that positively and negatively regulate cell differentiation and the signaling networks that are regulated by those factors. Because the molecular mechanisms of dedifferentiation by auxin and cytokinin have not been fully identified, further work will also involve detailed analysis of WIND, WUS, and TCP functions. Control of totipotency of plant cells is also important for breeding, production of new cultivars, and genetic engineering.

\section{REFERENCES}

Aida, M., Ishida, T., Fukaki, H., Fujisawa, H., and Tasaka, M. (1997). Genes involved in organ separation in Arabidopsis: an analysis of the cup-shaped cotyledon mutant. Plant Cell 9, 841-857. doi: 10.1105/tpc.9.6.841

Busch, W., Miotk, A., Ariel, F. D., Zhao, Z., Forner, J., Daum, G., et al. (2010). Transcriptional control of a plant stem cell niche. Dev. Cell 18, 841-853. doi: 10.1016/j.devcel.2010.03.012

Byrne, M. E., Barley, R., Curtis, M., Arroyo, J. M., Dunham, M., Hudson, A., etal. (2000). Asymmetric leaves1 mediates leaf patterning and stem cell function in Arabidopsis. Nature 408, 967-971. doi: 10.1038/ 35050091

Crawford, B. C., Nath, U., Carpenter, R., and Coen, E. S. (2004). CINCINNATA controls both cell differentiation and growth in petal lobes and leaves of Antirrhinum. Plant Physiol. 135, 244-253. doi: 10.1104/pp.103.036368

Cubas, P. (2000). "Role of genes in the evolution of morphological characters in angiosperm," in Developmental Genetics and Plant Evolution, eds Q. C. B. Cronk, R. M. Bateman, and J. A. Hawkins (London: Taylor and Francis), 247-266. 
Cubas, P., Lauter, N., Doebley, J., and Coen, E. (1999). The TCP domain: a motif found in proteins regulating plant growth and development. Plant J. 18, 215-222. doi: 10.1046/j.1365-313X.1999.00444.X

Doebley, J., Stec, A., and Hubbard, L. (1997). The evolution of apical dominance in maize. Nature 386, 485-488. doi: 10.1038/ 386485a0

Gallois, J. L., Nora, F. R., Mizukami, Y., and Sablowski, R. (2004). WUSCHEL induces shoot stem cell activity and developmental plasticity in the root meristem. Genes Dev. 18, 375-380. doi: 10.1101/gad.291204

Haecker, A., Gross-Hardt, R., Geiges, B., Sarkar, A., Breuninger, H., Herrmann, M., et al. (2004). Expression dynamics of WOX genes mark cell fate decisions during early embryonic patterning in Arabidopsis thaliana. Development 131, 657-668. doi: 10.1242/dev.00963

Hagen, G., and Guilfoyle, T. (2002). Auxin-responsive gene expression: genes, promoters and regulatory factors. Plant Mol. Biol. 49, 373-385. doi: 10.1023/A:1015207114117

Hiratsu, K., Matsui, K., Koyama, T., and Ohme-Takagi, M. (2003). Dominant repression of target genes by chimeric repressors that include the EAR motif, a repression domain, in Arabidopsis. Plant J. 34, 733-739. doi: 10.1046/j.1365313X.2003.01759.x

Holt, A. L., van Haperen, J. M., Groot, E. P., and Laux, T. (2014). Signaling in shoot and flower meristems of Arabidopsis thaliana. Curr. Opin. Plant Biol. 17, 96-102. doi: 10.1016/j.pbi.2013.11.011

Ikeda, M., Mitsuda, N., and Ohme-Takagi, M. (2009). Arabidopsis WUSCHEL is a bifunctional transcription factor that acts as a repressor in stem cell regulation and as an activator in floral patterning. Plant Cell 21, 3493-3505. doi 10.1105/tpc.109.069997

Iwase, A., Mitsuda, N., Koyama, T., Hiratsu, K., Kojima, M., Arai, T. et al. (2011). The AP2/ERF transcription factor WIND1 controls cell dedifferentiation in Arabidopsis. Curr. Biol. 21, 508-514. doi: 10.1016/j.cub.2011. 02.020

Kosugi, S., and Ohashi, Y. (1997). PCF1 and PCF2 specifically bind to cis elements in the rice proliferating cell nuclear antigen gene. Plant Cell 9, 1607-1619. doi: 10.1105/tpc.9.9.1607

Kosugi, S., and Ohashi, Y. (2002). DNA binding and dimerization specificity and potential targets for the TCP protein family. Plant J. 30, 337-348. doi: 10.1046/j.1365-313X.2002.01294.x

Koyama, T., Furutani, M., Tasaka, M., and Ohme-Takagi, M. (2007). TCP transcription factors control the morphology of shoot lateral organs via negative regulation of the expression of boundary-specific genes in Arabidopsis. Plant Cell 19, 473-484. doi: 10.1105/tpc.106.044792

Koyama, T., Mitsuda, N., Seki, M., Shinozaki, K., and Ohme-Takagi, M. (2010). TCP transcription factors regulate the activities of ASYMMETRIC LEAVES1 and miR164, as well as the auxin response, during differentiation of leaves in Arabidopsis. Plant Cell 22, 3574-3588. doi: 10.1105/tpc.110.075598

Larue, C. T., Wen, J., and Walker, J. C. (2009). A microRNA-transcription factor module regulates lateral organ size and patterning in Arabidopsis. Plant J. 58, 450-463. doi: 10.1111/j.1365-313X.2009.03796.x

Laux, T., Mayer, K. F., Berger, J., and Jurgens, G. (1996). The WUSCHEL gene is required for shoot and floral meristem integrity in Arabidopsis. Development 122, $87-96$.

Leibfried, A., To, J. P., Busch, W., Stehling, S., Kehle, A., Demar, M., et al. (2005). WUSCHEL controls meristem function by direct regulation of cytokinininducible response regulators. Nature 438, 1172-1175. doi: 10.1038/nature04270

Luo, D., Carpenter, R., Vincent, C., Copsey, L., and Coen, E. (1996). Origin of floral asymmetry in antirrhinum. Nature 383, 794-799. doi: 10.1038/383794a0

Mayer, K. F., Schoof, H., Haecker, A., Lenhard, M., Jurgens, G., and Laux, T. (1998). Role of WUSCHEL in regulating stem cell fate in the Arabidopsis shoot meristem. Cell 95, 805-815. doi: 10.1016/S0092-8674(00)81703-1
Nath, U., Crawford, B. C., Carpenter, R., and Coen, E. (2003). Genetic control of surface curvature. Science 299, 1404-1407. doi: 10.1126/science. 1079354

Nikovics, K., Blein, T., Peaucelle, A., Ishida, T., Morin, H., Aida, M., et al. (2006). The balance between the MIR164A and CUC2 genes controls leaf margin serration in Arabidopsis. Plant Cell 18, 2929-2945. doi: 10.1105/tpc.106. 045617

Nomura, K., and Komamine, A. (1986). Somatic embryogenesis in cultured carrot cells. Dev. Growth Differ. 28, 511-517. doi: 10.1111/j.1440-169X.1986.00511.x

Palatnik, J. F., Allen, E., Wu, X., Schommer, C., Schwab, R., Carrington, J. C., et al. (2003). Control of leaf morphogenesis by microRNAs. Nature 425, 257-263. doi: 10.1038 /nature 01958

Reddy, G. V. (2008). Live-imaging stem-cell homeostasis in the Arabidopsis shoot apex. Curr. Opin. Plant Biol. 11, 88-93. doi: 10.1016/j.pbi.2007. 10.012

Schoof, H., Lenhard, M., Haecker, A., Mayer, K. F., Jurgens, G., and Laux, T. (2000). The stem cell population of Arabidopsis shoot meristems in maintained by a regulatory loop between the CLAVATA and WUSCHEL genes. Cell 100, 635-644. doi: 10.1016/S0092-8674(00)80700-X

Stappenbeck, T. S., and Miyoshi, H. (2009). The role of stromal stem cells in tissue regeneration and wound repair. Science 324, 1666-1669. doi: 10.1126/science. 1172687

Takahashi, K., and Yamanaka, S. (2006). Induction of pluripotent stem cells from mouse embryonic and adult fibroblast cultures by defined factors. Cell 126, 663676. doi: 10.1016/i.cell.2006.07.024

Veit, B. (2004). Determination of cell fate in apical meristems. Curr. Opin. Plant Biol. 7, 57-64. doi: 10.1016/j.pbi.2003.11.009

Weijers, D., Benkova, E., Jäger, K. E., Schlereth, A., Hamann, T., Kientz, M., etal. (2005). Developmental specificity of auxin response by pairs of ARF and Aux/IAA transcriptional regulators. EMBO J. 24, 1874-1885. doi: 10.1038/sj.emboj.7600659

Yadav, R. K., Perales, M., Gruel, J., Ohno, C., Heisler, M., Girke, T., et al. (2013). Plant stem cell maintenance involves direct transcriptional repression of differentiation program. Mol. Syst. Biol. 9, 654. doi: 10.1038/ msb. 2013.8

Zhao, Z., Andersen, S. U., Ljung, K., Dolezal, K., Miotk, A., Schultheiss, S. J., et al. (2010). Hormonal control of the shoot stem-cell niche. Nature 465, 1089-1092. doi: $10.1038 /$ nature 09126

Zuo, J., Niu, Q. W., Frugis, G., and Chua, N. H. (2002). The WUSCHEL gene promotes vegetative-to-embryonic transition in Arabidopsis. Plant J. 30, 349-359. doi: 10.1046/j.1365-313X.2002.01289.x

Conflict of Interest Statement: The authors declare that the research was conducted in the absence of any commercial or financial relationships that could be construed as a potential conflict of interest.

Received: 26 June 2014; accepted: 12 August 2014; published online: 03 September 2014.

Citation: Ikeda M and Ohme-Takagi M (2014) TCPs, WUSs, and WINDs: families of transcription factors that regulate shoot meristem formation, stem cell maintenance, and somatic cell differentiation. Front. Plant Sci. 5:427. doi: 10.3389/fpls.2014.00427

This article was submitted to Plant Genetics and Genomics, a section of the journal Frontiers in Plant Science.

Copyright (c) 2014 Ikeda and Ohme-Takagi. This is an open-access article distributed under the terms of the Creative Commons Attribution License (CC BY). The use, distribution or reproduction in other forums is permitted, provided the original author(s) or licensor are credited and that the original publication in this journal is cited, in accordance with accepted academic practice. No use, distribution or reproduction is permitted which does not comply with these terms. 